\title{
Canny Helmet: A Sustainable Protection for New Generation
}

\author{
M.Divya pushpalakshmi, R.Ramalakshmi, V.Ramachandran
}

\begin{abstract}
The thought of developing this project came from social responsibility towards the society. As we can see many accidents occurring around us in our day-to-day life. Usually people die due to lack of treatment in proper time. The reasons for this may be many such as late arrival of ambulance, no person at place of accident to give information to the ambulance. Therefore, this paper came up with idea of giving the information about accident as soon as possible and in time. Thus, the death rate due to bike accident can be minimized. Here the vibration sensors in the helmet that are connected to Arduino board that delivers an input when the rider crashes. Based upon the sensor value, the Arduino extract GPS (Global Positioning System) data and then GSM (Global System for Mobile communication) module automatically sends message to ambulance, police and family members with GPS location. Then the accidents caused due to over fall of light at nighttime can also be avoided here by helmet equipped with the feature, automatic change of night mode visor. In addition, the android mobile communication can be done via Bluetooth module in the helmet.
\end{abstract}

Keywords: vibration sensor, GSM, GPS, Arduino, Ldr sensor, helmet.

\section{INTRODUCTION}

In today's life, people are busy in their own work. To accomplish that work, most of the people prefer two wheelers. Thus, the number of two wheelers users are increasing now a day. In addition, most of the youngsters are interested in bike riding. This trend leads to bike accidents as per the data cited in the report, the country recorded at least four, 80,652 accidents in 2016, leading to $1,50,785$ deaths [2]. The number suggests that at least 413 people died every day in 1,317 road accidents. Especially in India, according to a survey there are around 698 accidents occurring due to bike crashes per year [3]. Thus, the death rate in road accidents are increasing. Majority of the accidents happens because of the lack of consciousness and there is no helping hands in and around the place to inform the incidents. Similar work has been done in various paths such as e-call functions and software monitoring [4]. Alerting techniques using smart safety of common people in other aspects [5].To rectify this Problem GPS and GSM is interfaced within the Helmet to

Revised Manuscript Received on December 16, 2019.

* Correspondence Author

Divyapushpalakshmi*, Computer Science and Engineering, Kalasalingam Academy of Research and Education, Krishnankovil, India. Email: divyapushpalakshmi@gmail.com

R.Ramalakshmi, Computer Science and Engineering, Kalasalingam Academy of Research and Education, Krishnankoil, India. Email: rama@klu.ac.in

V.Ramachandran, Computer Science and Engineering, Kalasalingam Academy of Research and Education, Krishnankoil, India. Email: ramachandran.veer@gmail.com deliver a SMS with exact location. In addition, it is equipped with some smart features such as automatic change of night mode visor and Bluetooth attached with helmet.

\section{STATISTICS OF ROAD ACCIDENTS}

Psychiatric terms such as stress, sleeplessness, and depression are known to increase the possibilities of accidents in commercial facility [1]. According to the report compiled by the Transport Research Wing, the total number of road accidents in the country increased by $2.5 \%$ from 489,400 in 2014 to 501,423 in 2015[7]. The total number of persons killed in road accidents increased by $4.6 \%$ from 139,671 in 2014 to 146,133 in 2015[6]. Road accident injuries have also increased by $1.4 \%$ from 493,474 in 2014 to 500,279 in 2015 [8]. The severity of road accidents, measured in terms of number of persons killed per 100 accident has increased from 28.5 in 2014 to 29.1 in 2015 .

\section{Road Accident Deaths, By Mode Of Transport}

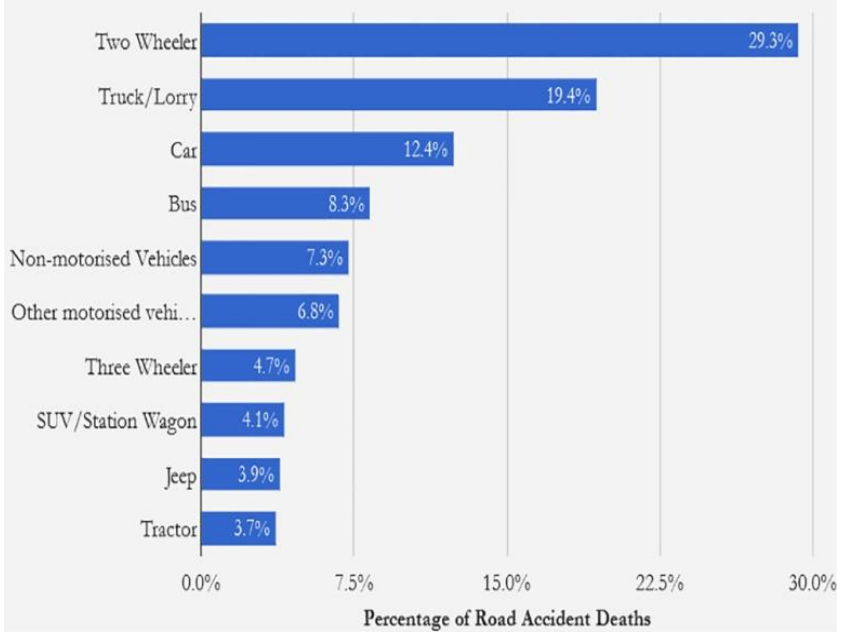

Fig. 1. Representation of two wheeler accident.

The number of road accidents caused by the two wheelers are increasing more than accidents caused by other vehicles. It accounts for $29.5 \%$. [14]. According to the statement of road transport, this situation will grow up in future. In order to reduce that situation and to save the life of the people, this system is implemented. 
Deaths On National And State Highways

national Highways - State Highways
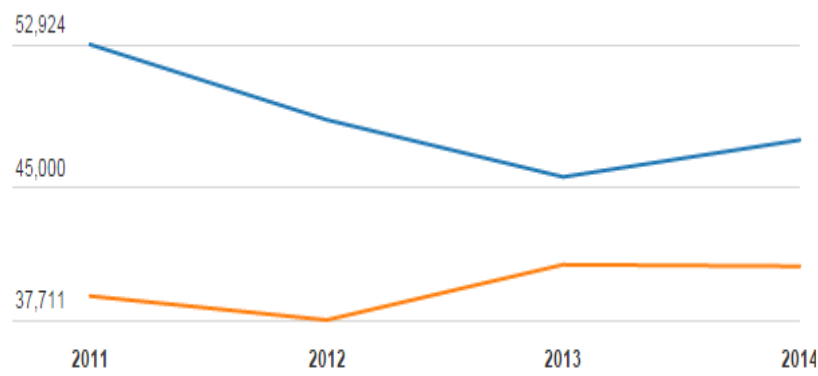

Fig. 2. Representation accident at highways.

\section{CANNY HELMET}

Helmet acts as a basic protection device for two-wheeler rider. It is developed with a GPS and GSM module, night mode visor, and Bluetooth. If someone unfortunately met with an accident then the location of that particular place will be sent to his or her relations as well as to nearby police station in the form of longitude and latitude values. In addition, the night mode visor change can reduce the bike crashes at nighttime. This helmet enable the person to communicate through android via the Bluetooth attached within the helmet.

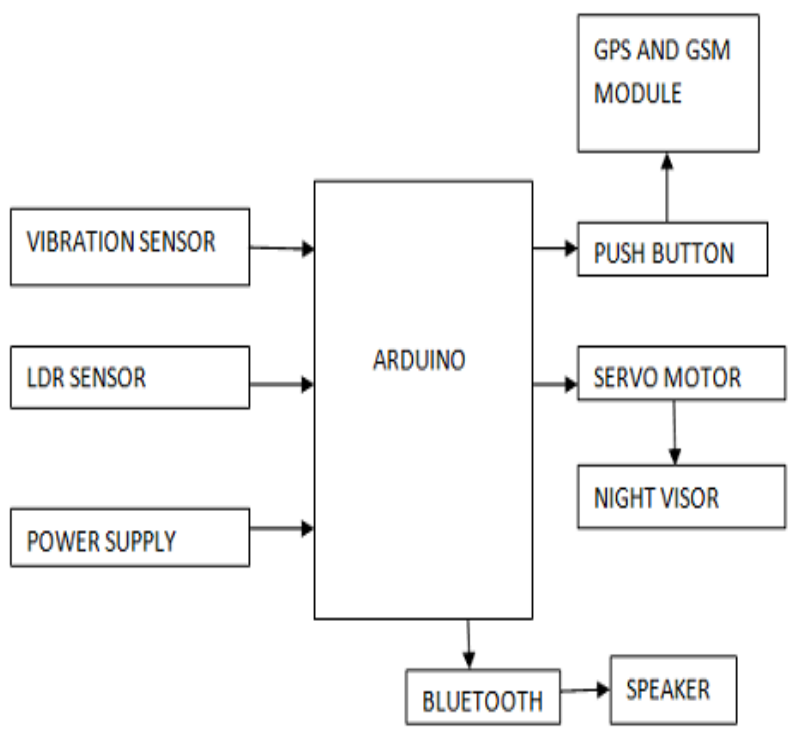

Fig. 3. Block diagram of canny helmet.

\section{PRINCIPLE OF OPERATIONS}

This canny helmet has an accident detection and technology developed feature. I.e. the accident detection system use a vibration sensor GPS and GSM module. The vibration sensor is used as input device to detect a vibration and the GPS and GSM delivers a message to the given numbers when it receives the vibration value from the sensor Moreover, the technology-developed feature is an automatic change of night mode visor. This feature consist of LDR sensor to sense the light intensity and servomotor is attached over the visor to lift up the visor. Based upon the light intensity, the visor can be lifted up and down. Here the Arduino acts as processing unit which fetches a input from the sensor and feeds the processed data to the output device to implement this systems.

\section{HARDWARE DESCRIPTION ARDUINO}

For processing the sensor values, every system needs a processing unit. So here, Adriano is used as processing unit. It is an open source. It can fetch the input the input data and feed the processed data to the output devices. It uses an ATMEGA328 microcontroller, digital pins, analogue pins, power supply and ground pin.

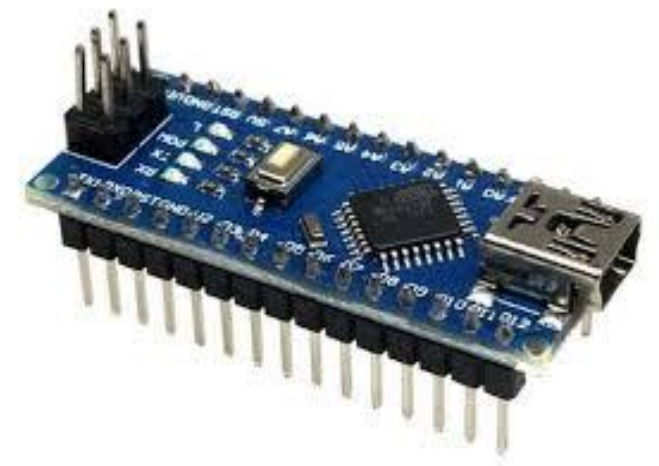

Fig. 4. Arduino Nano

\section{A.VIBRATION SENSOR}

This sensor is used to detect vibration in biker's helmet. Vibration Sensor outputs a logic HIGH when vibration was detected. We can use any of Arduino pins to read the data. Its operating voltage is $5 \mathrm{v}$.it consist of three pins. The purpose of pin is Vcc for receiving power, one is for ground connection, and another pin for transmitting and receiving a data .A wide dynamic range $(0.001 \mathrm{~Hz} 1000 \mathrm{MHz})$ guarantees an excellent measuring performance [12][17]. In addition, the value can be adjusted its sensitivity by adjusting the on-board potentiometer with a screw. It is an effective sensor to detect the vibration. 


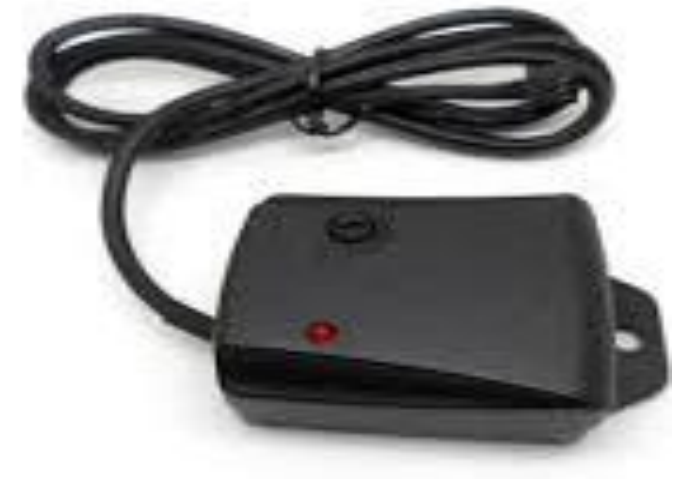

Fig. 5. vibration sensor

\section{B. GPS AND GSM MODULE SIM808}

The Global Positioning System (GPS) is a satellite-based navigation system, which is used to detect the location where the accident will be taken place [16]. It detects the Longitude and Latitude values of particular place and sends it to GSM module. It works in all weather conditions. It is a well-designed device, which consist of GPS antenna to search for a location .This, is in interfaced with GSM module.

GSM abbreviates as Global System for Mobile communication. It is used to establish connection between a computer and GSM system [20]. It includes standard interfaces like RS232, USB, etc. The power supply circuit is also built in the module that can be activated by using a suitable adaptor. It operates on $3.3 \mathrm{v}$ to $4 \mathrm{vIt}$ [11]. Consist of supply, ground, transmission and reception pin. It is used to send messages through the SIM. Message receiving SIM number was already initialized in the coding of GSM module. Thus, it sends the message about the accidents with exact location.

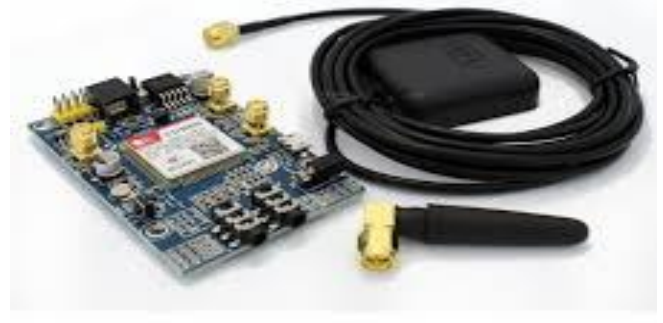

Fig. 6. GPS and GSM moduleSIM808

\section{SIM}

SIM abbreviates as Subscriber Identity Module. It is a small chip placed inside GSM module [10]. It is used to send the location to the relatives of victim and nearby police station where the accident has occurred. Nowadays, SIM is an easily available thing .so usage of GSM with SIM within the helmet is feasible and safe.

\section{PUSH BUTTON}

The push button is three-pin device that gives an output as high when it is pressed. It consist of two states like a switch such as high and low i.e. on and off [18]. Here it is used as intermediate device in between the Arduino and GSM and GPS module.

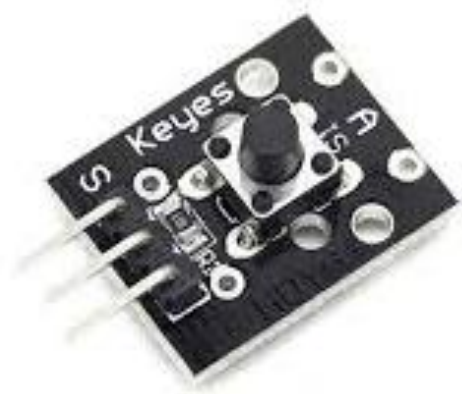

Fig. 7. Push button

\section{E. LDR SENSOR:}

The LDR sensor is a type of sensor used to find the light intensity. This acts as an input device to detect whether it is a day or night based upon the brightness. It passes an input over the Arduino when it gets the light intensity [15]. It may be high or low. Here LDR sensor input can enable the visor to move up and down.

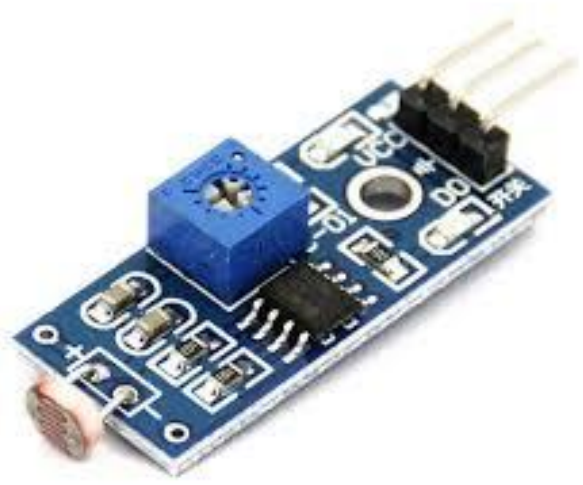

Fig. 8. LDR sensor

\section{F. SERVO MOTOR}

A servomotor is a rotary actuator or linear actuator that allows for precise control of angular or linear position. It consists of suitable motor coupled to a sensor for position feedback. It can rotate with particular angle [19]. The force exposed by the servo motor is enough to implement the automatic change of night mode visor. The rotation of this helps to move the visor up and down based upon the light intensity value delivered by ldr sensor.

Published By:

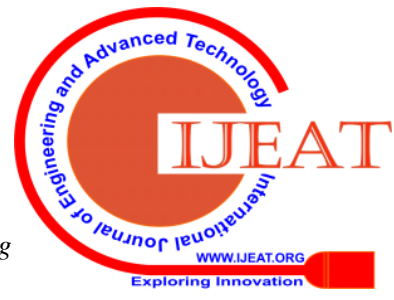




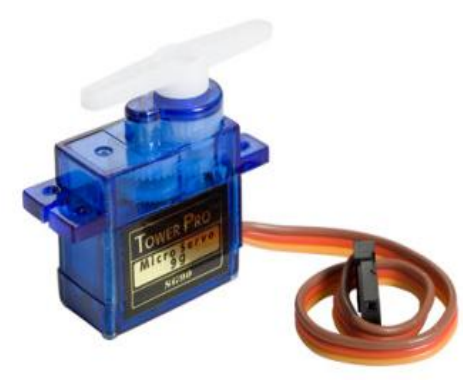

Fig. 9. Servo motor

\section{G. POWER SUPPLY/POWER ADAPTER}

Power supply is the source of electrical power. An electrical battery is a power source which can be charged, discharged into a load, and recharged many times, as opposed to a disposable or primary battery, which is supplied fully charged and discarded after use. It is composed of one or more electrochemical cells. Here, $5 \mathrm{~V}$ power supply is being used to give power over the devices. Current will flow in the circuit in the form of direct current (DC).

\section{METHODOLOGY AND WORKING PROCESS}

In this project, multiple features are added in order to rectify the lacking of treatment to the people who met with an accident and to develop the existing helmet with some smart features. So vibration sensor, Arduino, GPS and GSM module are integrated for the purpose of detecting and informing about the accidents. Here the vibration sensor sends a logic HIGH at time of sensing vibration and the Arduino passed a fetched input over the GPS and GSM. Module with SIM for sending a message about the detected accident. According to the statement of road transport of India, The main reason for the death in accidents are no person at accident spot to inform about an accident, no treatment at necessary time. This helmet with hi-tech system can rectify these problems. Push button is also introduced to rectify the problem of transformation of message when the helmet falls non-accidently. Then the servomotor attached with the visor can implement the automatic change of visor. In this implementation, ldr sensor sense and judge whether it is day or night. According to the data of LDR, Servomotor is rotated and expel a force to move a visor. The mobile communication can be done via Bluetooth module with speaker.

\section{FLOW DIAGRAM FOR ACCIDENT \\ DETECTION SYSTEM IN CANNY HELMET}

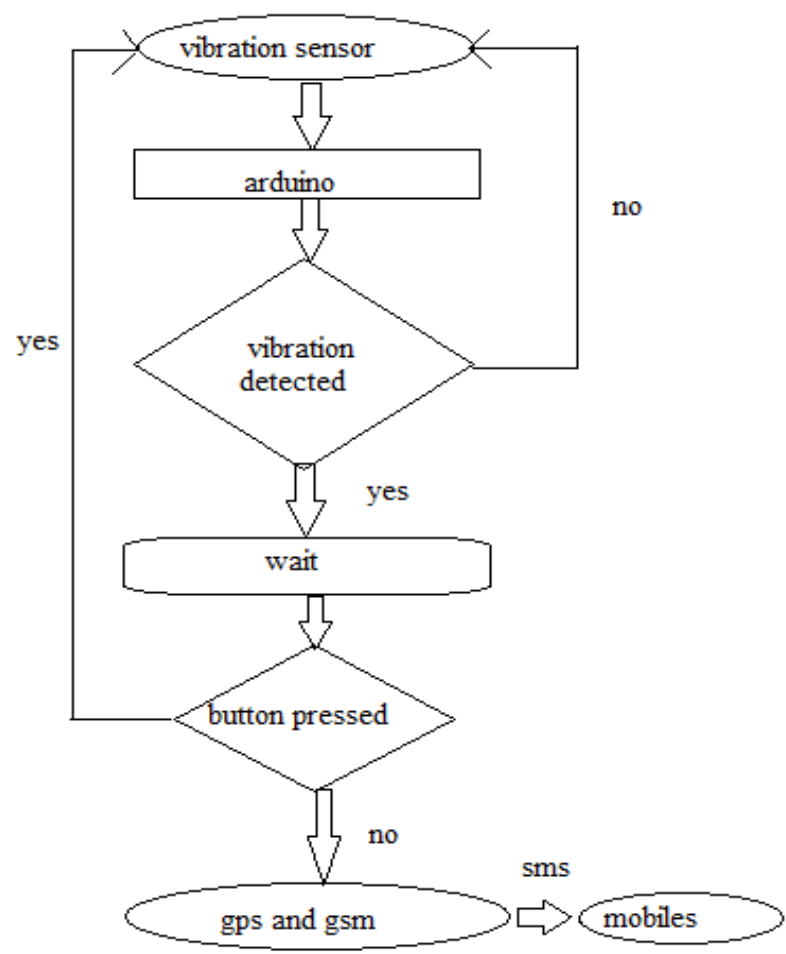

Fig.10. Flow diagram

\section{RESULT}

This module was completed to detect the accident system using push button, GSM and GPS, vibration sensor. Automation of visor was implemented by servomotor as a pull up force. These technologies can be served as awareness to the ambulance and family members by sending the SMS with exact location in accidental condition. These can be reduced the death of people in road accidents. The outcomes of this paper are can be shown by above image. 


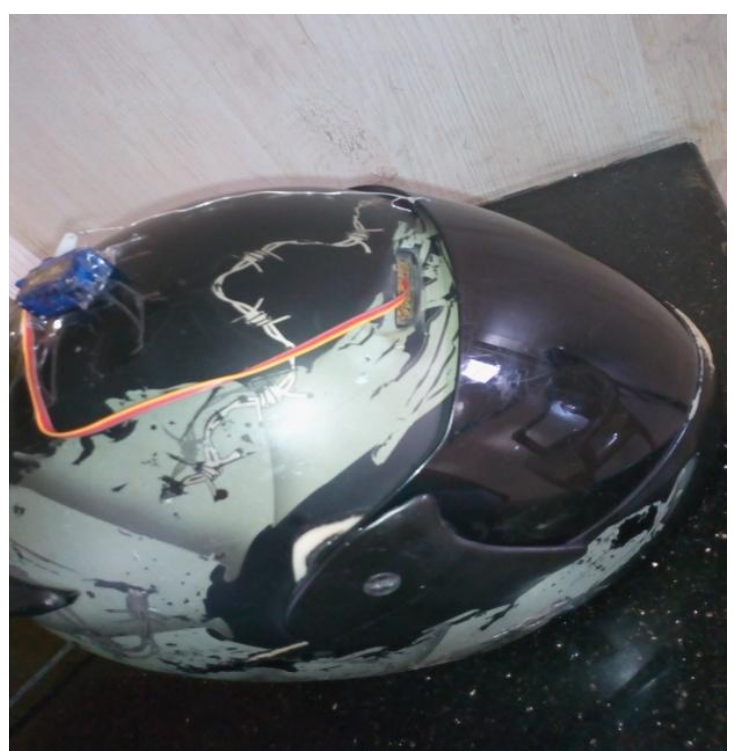

Fig.11. Image of real time implementation

\section{CONCLUSIONS}

This helmet can reduce number of road accidents that takes place every day. It ensures the safety of the biker as well as sends the victim's location to family members and nearby police station. In addition, death rate can drastically be reduced by this project. Moreover, it consist of some extra-ordinary feature as visor and Bluetooth attached system. These ideas can develop this project more feasible and it will be suitable for all the bikers.

\section{ACKNOWLEDGEMENT}

This is a great opportunity for us to express our sincere thanks to personality who was helped us from the very beginning to make this project. Hereby expressing our keen gratitude towards the respected guide Mr.V.Ramachandran, Director of "Yugti smart solution". We have been very fortunate to him for the whole support and heartily coordination, which triggered us for completion of the project.

\section{REFERENCE}

1. Li, P., Meziane, R., Otis, M. J. D., Ezzaidi, H., \& Cardou, P. (2014, October). A Smart Safety Helmet using IMU and EEG sensors for worker fatigue detection. In 2014 IEEE International Symposium on Robotic and Sensors Environments (ROSE) Proceedings (pp. 55-60). IEEE.

2. Yang, J., Jiang, Y., Zheng, R., Bi, Y., Hong, J., \& Yang, B. (2011). Sympathetic filament eruptions from a bipolar helmet streamer in the Sun. The Astrophysical Journal, 745(1), 9.

3. Verma, C., Yadav, P., Samrit, P., Karashi, S., \& Singh, D. (2017). Smart Helmet and Fingerprint Based Ignition System for Vehicles. I-Manager's Journal on Computer Science, 5(2), 12.

4. Cho, B. H. (2017). Design of Auto bike Driver's Driving Information and e-call Functions Providing Software using Smart Helmet. The Journal of the Institute of Internet, Broadcasting and Communication, 17(4), 173-179.

5. Jose, S. J., Rahul, A. S., \& Sajin, S. (2017). Safety and Alerting System of Vehicles Using a Smart Helmet. I-Manager's Journal on Wireless Communication Networks, 6(2), 28.

6. Pujar, H., Suhel, S., Dinakar, N., Baseganni, C., Gohil, M., \& Kulkarni, R. (2018). Novel Prototype of Mining Helmet to Facilitate Cooling. Advanced Journal of Graduate Research, 3(1), 3-8.
7. Bai, B. S. B. S., Basha, B. C. M., Thirumalaiah, K., Bharathi, N., \& Ramalakshmamma, A. (2018). Human Safety System for Two Wheeler. Journal of Microcontroller Engineering and Applications, 5(1), 25-31.

8. Indupuru, Y., Venkatasubramanian, K., \& Umamaheswari, V. (2018). Design and Implementation of Smart Helmet Using Low Power MSP430 Platform. In Intelligent Embedded Systems (pp. 211-223) Springer, Singapore.

9. D’Souza, A., \& Maliyackal, S. S. (2018). Helmet Integrated Bike Ignition Using Arduino. Proceedings of 4th International Conference on Energy Efficient Technologies for Sustainability-ICEETS'18. St.Xavier's Catholic College of Engineering, Nagercoil, TamilNadu, India, from 5 th to 7th April, 2018. Available in SSRN eLibrary of ELSEVIER.

10. Kumar, S. V. P. D., Vasavi, S., Akashe, S., \& Kumar, V. (2018). Advanced Control of Switching Ignition by Smart Helmet. International Journal of Image, Graphics \& Signal Processing, 10(2).

11. I-Helmet System With Vehicle Controlling and Accident Prevention Jishnu G, Anandhu K.S,Eldhose, Department Of Electronics and Communications Baselios Thomas1Catholicose College of Engineering and Technology Koothattukulam, Ernakulum - India, International Journal of Engineering Trends and Applications (IJETA) - Volume 4 Issue 2, Mar-Apr 2017.

12. Manjesh N1 , Prof. Sudarshan Raj2 1M Tech, ECE-DSCE, JNTUA, Hindupur, India 2HOD \& Asst. Prof. BIT-IT, Hindupur,india , "Smart helmet using gps and gsm technology" ,International Journal of Electrical and Electronics Research ISSN 2348-6988 (online) Vol. 2, Issue 4, pp: (122-127), Month: October - December 2016.

13. Ayush Garg ,Swati Gupta ,Harpreet Kaur , Chitkara Institute of Engineering and Technology, India , paper on "smart helmet", International Journal of Computer Applications (0975 - 8887) ,2016.

14. Mangesh Jadhawar, Gauri Kandepalli, Ashlesha Kohad3, Rajkumar Komati,MIT College of Engineering, ENTC Department, Pune ,presented paper on "smart helmet safety using atmega32" at International Journal of Research in Engineering and Technology eISSN: 2319-1163 | pISSN: 2321-7308, may 2016.

15. Paper on "Hi-tech Helmet and Accidental Free Transportation System" by Aviral Vijay*, Ajay Singh, Bhanwar Veer Singh, Abhimanyu Yadav, Blessy Varghese and Ankit at International Journal of Advanced Technology and Engineering Exploration ISSN (Print): 2394-5443 ISSN (Online): 2394-7454 Volume-2 Issue-6 May-2015.

16. Ping Li, Ramy Meziane, REPARTI Centre, University of Quebec at Chicoutimi, Canada, IEEE symposium on "A Smart Safety Helmet using IMU and EEG sensors for worker fatigue detection", November 2014.

17. Intelligent Automatic Vehicle Accident Detection System Using Wireless Communication" A.Rajkiran1, M.Anusha2 1Assistant Professor, Dept of ECE, MLRITM, Hyderabad, India. International Journal of Research Studies in Science, Engineering and Technology Volume 1, Issue 8, November 2014, PP 98-101.

18. Mohd Khairul Afiq Mohd Rasli,Nina Korlina Madzhi ,Juliana Johari Faculties of Electrical Engineering, University Technology MARA, 40450 Shah Alam Selangor, MALAYSIA, Electrical, Electronics and System Engineering (ICEESE), 2013 International Conference on "“" Smart helmet with sensors for accident prevention".

19. Vehicle Accident Alert and Locator "by Victor Olugbemiga (Ph.D.), Emmanuel ADETIBA (M.Eng. R.Eng.) Department of Electrical \& Information Engineering, College of Science and Technology, Covenant University, Ota, Nigeria. International Journal of Electrical \& Computer Sciences IJECS-IJENS Vol: 11 No: 02 IEEE Explore: 11, September 2014,

20. Automatic Vehicle Accident Detection And Messaging System Using GPS and GSM Modems” By Sri Krishna Chaitanya Varma, Poornesh, Tarun Varma at International Journal of Scientific \& Engineering Research, Volume 4, Issue 8, August-2013

\section{AUTHORS PROFILE}

Divyapushpalakshmi is a Full time researcher in Kalasalingam Academy of Research and Education, Lifetime member of ISTE; previously he has obtained his PG in Network Engineering in Kalasalingam University

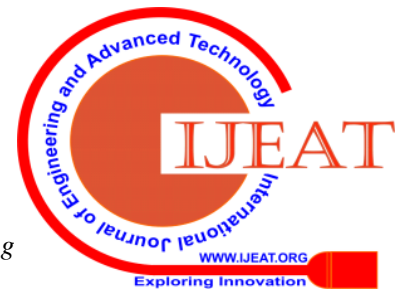


Dr Ramalakshmi Ramar is working as an Associate Professor in Kalasalingam Academy of Research and Education. She has published more than 15 Research articles in reputed conferences and high impact factor journals. Her research interest includes WSN, ADHOC networks, Data Analytics and Internet of Things.

Ramachandran Veerachamy is a Full time researcher in Kalasalingam Academy of Research and Education, Lifetime member of ISTE; previously he has obtained his PG in Network Engineering in Kalasalingam University 